\title{
EFFECT OF TEXTURE ON YIELD POINT PHENOMENA IN SOME ZIRCONIUM ALLOYS.
}

J.J. FUNDENBERGER, M. J. PHILIPPE and C. ESLING.

Laboratoire de Métallurgie des Matériaux Polycristallins. ISGMP, UFR MIM-Sciences

Ile du Saulcy

F- 57045 METZ CEDEX.

\section{Introduction}

As opposed to the cases of the face-centered and bodycentered cubic metals, studies of yield point phenomena arising in the hexagonal metals have received relatively poor attention.

The tensile curves of zirconium alloys can present very different shapes in the vicinity of the yield point : with or without yield drop, with yield drop and more or less extended stage in which Luders bands form $(1,2)$. Beside the well known effect of intersticials $(3,4,5)$, we observe that the tensile curves are often, for the same material and even the same metallurgical state, very different in rolling and transverse direction.

The present work is aimed at pointing out the influence of the crystallographic texture on the behaviour of zirconium alloy sheets at the yield point. These alloys have undergone various thermomecanical treatments in order to obtain materials having different crystallographic textures but similar grain sizes. We give here an example of two sheets of the same $\mathrm{Zr}$ alloy. These two sheets have been cold worked by two different processes and finally annealed. The resulting textures are either of C-type, (c axes near or parallel to the normal direction), or of T-type (c axes tilted about $30^{\circ}$ towards the transverse direction in the (ND,TD) plane) (fig. 1).

From these sheets we cut samples in rolling and transverse directions. The stress-strain curves obtained by tensile tests are dependent on the texture type.

We note that the C-type texture samples show smooth stressstrain curves, with no marked yield point. The shape of the 
curves and the $s_{0.2}$ yield limits are identical for the samples, be they cut in RD or in TD, due to the relative isotropy induced by the central texture. The smoothness of the curves makes it difficult to identify the yield limit (fig. 2).

Samples with the T-type texture show sharp stress-strain curves with a marked yield point and even a marked yield drop. The shape of the curves and the $s_{0.2}$ yield limits are much different, according to whether the samples are cut in RD or in TD due to the texture. The yield drop is larger in the case of TD stretching, the $\mathrm{s}_{0.2}$ is also higher in this direction (fig. 3).

In the case of the 702 grade zirconium with a transverse texture the deformation at room temperature occurs essentially by prismatic gliding. Moreover, about $90 \%$ of the grains have an orientation close to $\{1106\}<1120\rangle$ and the values of the orientation factor of two prismatic glides out of three range from 0.40 to 0.43 for stretching in the D.L. direction and from 0.33 to 0.37 for stretching T.D. It is thus possible to argue about the activation of the various glide systems with regard to the above mentioned ideal orientation. So, even if a few grains show higher orientation factors they do not noticeably contribute to the plastic deformation as they only represent a small proportion of the grains. When the applied stress reaches a value in the order of

$$
\sigma_{\mathrm{appl}}=\frac{\tau_{\mathrm{c}} \text { pris m }}{\mathbf{f}_{\mathrm{s}}}
$$

where $\tau$ prism denotes the CRSS for prismatic glide and $f_{s}$ denotes the Schmid factor corresponding to the above mentioned ideal orientation, all grains start to deform plastically.

While the stress is high enough to provoke the gliding of the dislocations in these grains, the density $q$ of the concerned dislocations increases to such an extent that the stress drops in order to ensure the condition $\dot{\varepsilon}=$ constant which is imposed by the stretching machine. In addition geometrical softening occurs as the $\langle 1010\rangle$ axis rotates $15^{\circ}$ and then $30^{\circ}$ around the $\mathrm{c}$ axis during the first $4 \%$ of the deformation. The orientation factors take respectively the values: $0.43,0.5$, and 0.43 in a stretching in R.D. direction. For instance, it should be mentioned that the relations

$$
\sigma_{\mathrm{u}} \text { i n RD }=\frac{\tau_{\mathrm{cprism}}}{0,43} \text { and } \sigma_{\mathrm{u}} \text { i n } \mathrm{TD}=\frac{\tau_{\mathrm{cp} \text { ris m }}}{0,36}
$$


are well fulfilled. This explains well that $\sigma_{u}$ is higher in T.D. than R.D.

In the case of a c-type texture the components are not so sharp and are more spread out. Thus the orientation factors in the crystallites range continuously from 0.3 to 0.5 (this holds as well for stretching in an R.D. direction as for in a T.D. direction). When the C.R.S.S. for a prismatic glide is reached in the grains with orientation factors close to 0.5 , the latter start to deform plastically (about $10 \%$ of the grains have an orientation factor higher than 0.48 ). When the applied stress increases further, plastic deformation progressively reaches all the grains.This accounts for the various shapes observed in the stretching curves at room temperature.

\section{Conclusion}

Yield phenomena have been studied in several Zirconium alloys. For each alloy, if all the other parameters are kept constant, the texture plays a decisive role on the existence of a yield drop. For instance in the case of a cold rolled and recrystallized Zircaloy 4 sheet with C-type texture (c-axes parallel to ND), the yield point is not well defined. When the same alloy shows a texture with c-axes tilted in the (ND,TD) plane the yield point is marked with a plateau particularly developed when stretching a sample cut in TD at room temperature.

When comparing yield stresses and taking into consideration the major component of these strong textures, the effect of the texture can be understood by means of the activation of prismatic gliding.

\section{Literature}

(1) J.J. Goncalves, These CNAM Paris (1981)

(2) M.J. Philippe, F.E. Mellab, F. Wagner, C. Esling and B. Hocheid, Proceedings of sixth world conference on TITANIUM, Les Editions de Physiques, p. 135 (1988)

(3) J. Pokorny, Rapport IRSID, pp. 74-131 (1974)

(4) E.O. Hall, Yield Point Phenomena in Metals and Alloys, Editions Macmillan (1970)

(5) J. Benard, A. Michel, J. Philibert et J. Talbot, Métallurgie Générale, Editions Masson, p. 179 (1984) 


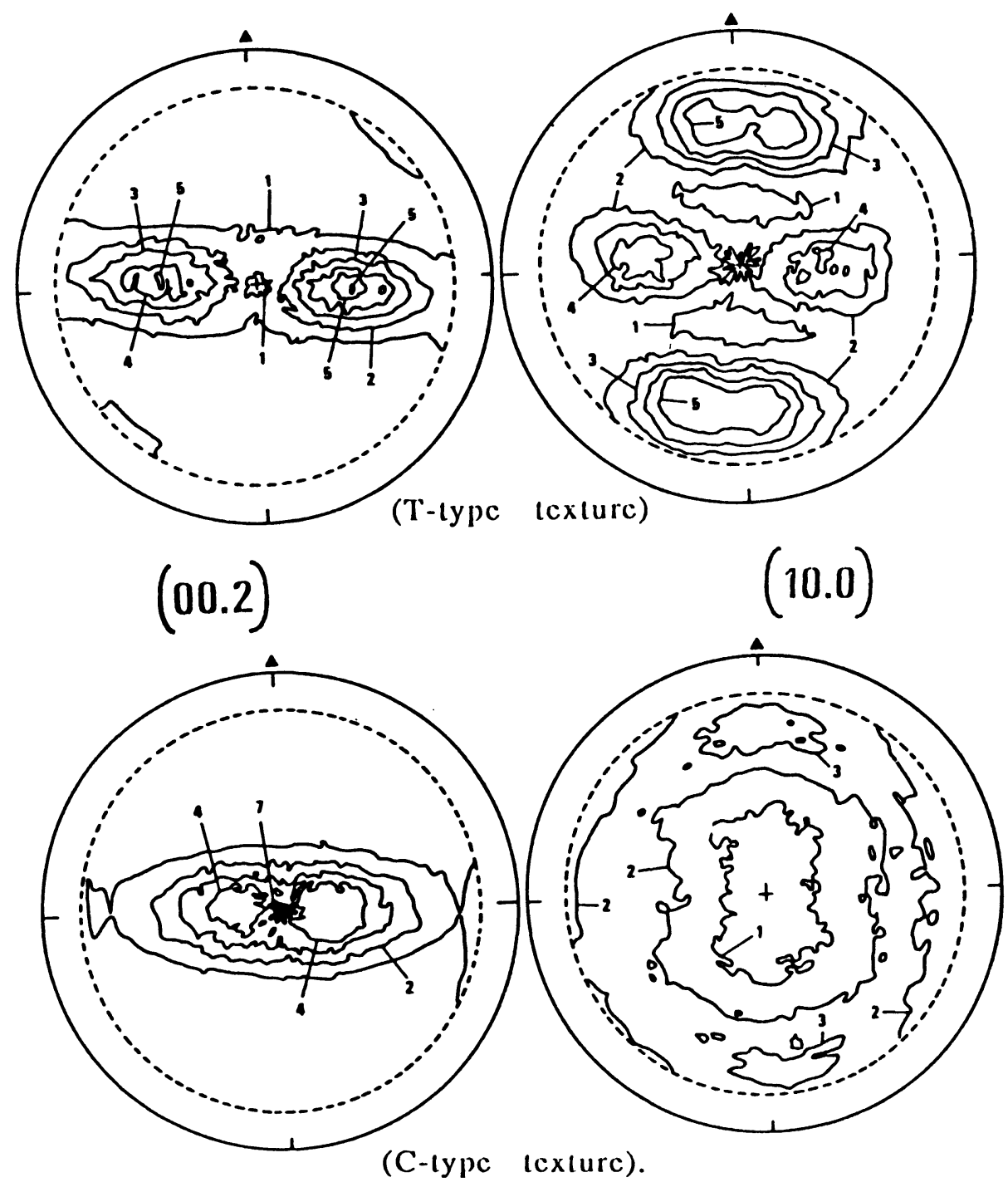

Figure 1 : Textures of the $\mathrm{Zr} 702$ after unidircctional-rolling and anncaling (T-type texturc) and after cross-rolling and anncaling (C-typc tcxturc). 


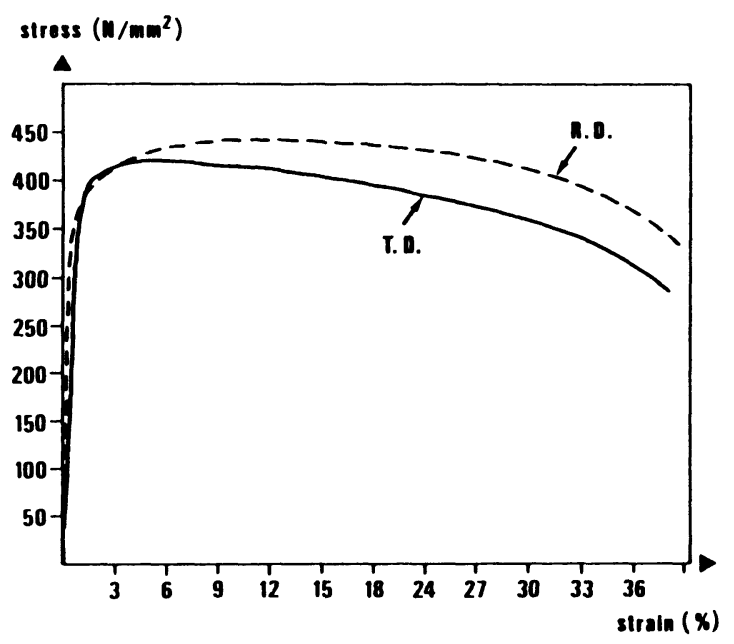

Figurc 2 : Strctching curves at room tempcrature on $\mathrm{Zr} 702$ with C-type texturc. Samples are cut in RD and in TD.

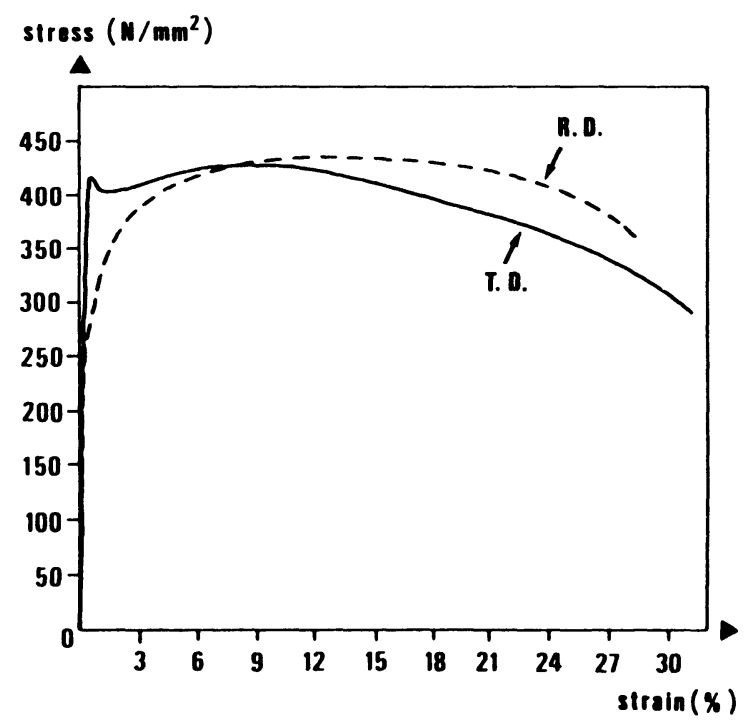

Figurc 3 : Strctching curves at room tempcrature on $\mathrm{Zr} 702$ with T-type texture. samples are cut in RD and in TD. 